\title{
The competition between syntax and rhythm in iGeneration Taiwanese
}

\author{
Yuchao E. Hsiao*
}

\begin{abstract}
This paper addresses the syntactic and rhythmic conditions on prosodic restructuring in iGeneration Taiwanese. The iGeneration, who grew up with an iPhone, or a smartphone, in hand, is loosely referred to people born between 1995 and 2005. The speakers of iGeneration Taiwanese tend to parse them into short fragments, which correspond to smaller phonological phrases. The categorical distinction between lexical and functional projections plays a role in phonological phrasing. Rhythmic restrictions then serve to avoid an oversized phonological phrase. In this paper, I posit a series of alignment and rhythm constraints, and offer an analysis through constraint interaction.
\end{abstract}

Keywords. phonological phrase; tone, alignment; constraint; syntax; rhythm; iGeneration Taiwanese

1. Introduction. The syntactic influence on phonology has been widely observed. This paper presents a clear case of the competition between syntax and rhythm on prosodic restructuring, drawing on evidence from iGeneration Taiwanese. The Southern Min dialect spoken by the majority of the population in Taiwan is known as general Taiwanese (Ang 2003). The iGeneration is loosely referred to people born between 1995 and 2005; they grew up with an iPhone, or a smartphone, in hand, and are also known as Generation Z, Post-Millennials, or Homeland Generation (Wallop 2014, Blad 2016, White 2016, and others).. The iGeneration Taiwanese speakers seldom produce long utterances, but tend to parse them into short fragments, which serve as the tone sandhi domains. Questions then arise as to whether the short fragments are syntactically defined, and to what extent they are rhythmically restricted. In the following discussions, I will first present some background of the tones and tone sandhi domain. I will then discuss the syntactic and rhythmic effects on the phonological phrasing in relation to functional projection. Finally, I will offer an analysis through constraint ranking under the optimality theory (Prince \& Smolensky 1993/2004).

2. Some background. General Taiwanese and Taiwan Mandarin are the most dominant dialects in Taiwan; they have interacted in this island for over seventy years, but are not mutually intelligible. In iGeneration Taiwanese, an adjusted sound system between these two dialects is developed, including the loss of checked tones. A checked syllable ends in a glottal or unreleased voiceless stop, such as [?], [p], [t] and [k], and a tone carried by a checked syllable is known as a checked tone. An open syllable or a syllable that ends in a sonorant is known as a smooth syllable, and a tone carried by a smooth syllable is known as a smooth tone. The inventory of iGeneration Taiwanese has five smooth tones, each of which corresponds to a sandhi tone. The paradigm in (1) shows the disyllabic tone sandhi.

\footnotetext{
* I would like to thank the Ministry of Science and Technology in Taiwan for sponsoring this research, under the grant MOST\#107-2410-H-004-115-MY2. I would also like to thank my research assistants, Wang-chen Ling, Tzuchuan Huang, Yi Jen Chen, Tei-Wei Yeh, Zhong-Liang Gao and Xin-Rong Wu, for their enthusiastic help. Thanks also go to the participants of LSA-2020 for very useful discussions. Author: Yuchau E. Hsiao, National Chengchi University, Taipei (ychsiao@nccu.edu.tw).
} 
(1)

Disyllabic Tone Sandhi

\begin{tabular}{|c|c|c|c|c|c|}
\hline & 55 & 33 & 21 & 53 & 13 \\
\hline 55 & $\begin{array}{l}\mid \text { tsin sio } \\
3355 \\
\text { 'very hot' }\end{array}$ & $\begin{array}{l}\text { tsin zun } \\
3333 \\
\text { 'very tough' }\end{array}$ & $\begin{array}{l}\text { tsin tshao } \\
3321 \\
\text { 'very smelly' }\end{array}$ & $\begin{array}{l}\text { tsin sui } \\
3353 \\
\text { 'very pretty' }\end{array}$ & \begin{tabular}{|l} 
tsin thui \\
3313 \\
'very silly'
\end{tabular} \\
\hline 33 & $\begin{array}{l}\text { sun hong } \\
2155 \\
\text { 'downwind' }\end{array}$ & $\begin{array}{l}\text { sun lo } \\
2133 \\
\text { 'on the way' }\end{array}$ & \begin{tabular}{|l} 
sun swa \\
2121 \\
'on one's way'
\end{tabular} & \begin{tabular}{|l} 
sun tshiu \\
2153 \\
'smoothly'
\end{tabular} & $\begin{array}{l}\text { sun kiann } \\
2113 \\
\text { 'safe trip' }\end{array}$ \\
\hline 21 & $\begin{array}{l}\text { am an } \\
53 \text { 55 } \\
\text { 'good night' }\end{array}$ & $\begin{array}{l}\text { am ho } \\
5333 \\
\text { 'signal' }\end{array}$ & 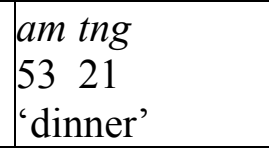 & $\begin{array}{l}\text { am hong } \\
53 \quad 53 \\
\text { 'secret visit' }\end{array}$ & $\begin{array}{l}\text { am } m i \\
53 \quad 13 \\
\text { 'night' }\end{array}$ \\
\hline 53 & $\begin{array}{l}\text { hue ke } \\
5555 \\
\text { 'turkey' }\end{array}$ & $\begin{array}{l}\text { hue tshiu } \\
5533 \\
\text { 'fire tree' }\end{array}$ & $\begin{array}{l}\text { hue thuann } \\
5521 \\
\text { 'fire carbon' }\end{array}$ & $\begin{array}{l}\text { hue thui } \\
55 \quad 53 \\
\text { ‘ham' }\end{array}$ & $\begin{array}{l}\text { hue lo } \\
55 \text { l } 13 \\
\text { 'stove' }\end{array}$ \\
\hline 13 & $\begin{array}{l}\text { ang hue } \\
3355 \\
\text { 'red flower' }\end{array}$ & $\begin{array}{l}\text { ang nng } \\
3333 \\
\text { 'red egg' }\end{array}$ & \begin{tabular}{|l} 
ang suann \\
3321 \\
'red thread'
\end{tabular} & $\begin{array}{l}\text { ang tsiu } \\
3353 \\
\text { 'red wine' }\end{array}$ & $\begin{array}{l}\text { ang te } \\
3313 \\
\text { 'black tea' }\end{array}$ \\
\hline
\end{tabular}

In terms of Chao's (1930) tone transcription system, 5 represents high, 3 represents mid, and 1 represents low; 4 can b can be either high or mid and 2 can be either mid or low, depending on the tone inventory of a language. The tone sandhi reveals a series of chain shifts, as summarized in (2). (cf. also Chen 1987, 2000, Hsieh 2005, Barrie 2006, Alderete 2008, Thomas 2008, Hsiao 1991, 1995, 2015, among others, for further discussions of the chain shifts).

(2) Chain shifts: $13 \rightarrow 33 \rightarrow 21 \rightarrow 53 \rightarrow 55 \rightarrow 33$

The disyllabic tone sandhi can be generalized as follows: given a pair of adjacent tones, $\mathrm{T}_{1}$ and $T_{2}$, the left tone $\left(T_{1}\right)$ occurs in its sandhi form, while the right tone $\left(T_{2}\right)$ retains its base form, as summarized by the schema in (3).

(3) Tone Sandhi Rule: $\mathrm{B} \longrightarrow \mathrm{S} /$

B (B: base tone; S: sandhi tone)

Selkirk (1986) proposes a set of end-based parameters which mark the break of a phonologi-

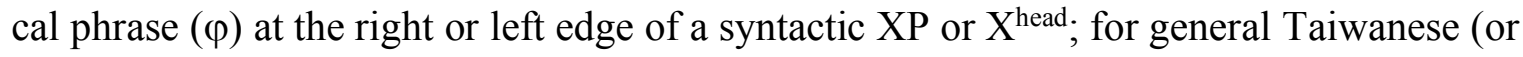
Xiamen), the $\varphi$-break coincides with the right edge of a nonadjunct XP (Hsiao 1991, 1995, Chen 2000).

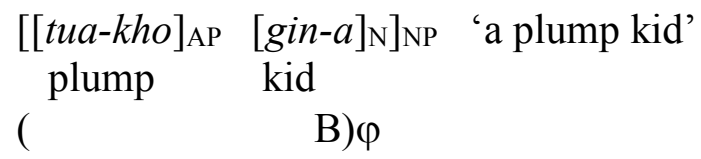

The AP tua-kho in (4) is an adjunct modifying its noun head gin- $a$, and thus is not $\varphi$-marked. The entire NP forms a single phonological phrase, in which only the final syllable $-a$ retains its base tone, while all the preceding syllables surface with their sandhi tones.

3. Functional projection. Under the X-bar theory, the projection of a lexical head, such as a noun, a verb, an adjective and a preposition, is referred to as a lexical projection, $\mathrm{XP}_{\mathrm{Lex}}(\mathrm{VP}, \mathrm{NP}$, AP and PP), while that of a functional head, such as a classifier, a complementizer, a determiner, 
an inflectional property (tense or agreement), is referred to as a functional projection, $\mathrm{XP}_{\text {Fun }}$ (CLP, CP, DP and IP) (cf. Chomsky 1986, Abney 1987, Ouhalla 1990). Truckenbrodt (1999) and Selkirk (2011) suggest that a phonological phrase corresponds to a lexical projection, but not a functional projection. In this sense, it is understandable that the DP in (5) and the CLP in (6) do not end in $\varphi$-breaks.

$$
\begin{aligned}
& \text { ho gua }]_{\mathrm{DP}} \text { tshao-soh 'give me ropes' } \\
& \text { give me rope } \\
& \text { ( } \quad \text { B) } \varphi \text { Phonological Phrase } \\
& \text { (6) neng tiao }]_{\mathrm{CLP}} \text { tshao-soh 'two ropes' } \\
& \text { two CL rope } \\
& \text { ( B) } \varphi
\end{aligned}
$$

However, problems arise from (7) and (8).

$$
\begin{aligned}
& \text { ho gua } \left.]_{\mathrm{DP}} \text { neng tiao }\right]_{\mathrm{CLP}} \text { tshao-soh } \\
& \text { give me two CL rope } \\
& \left(\begin{array}{lll}
\text { B } \varphi( & \text { B) } \varphi
\end{array}\right.
\end{aligned}
$$

(8) kuann-kin ho gua] $]_{\mathrm{DP}}$ neng tiao]CLP tshao-soh quickly give me two CL rope
$\left(\begin{array}{lll}\text { B }) \varphi( & \text { B }) \varphi\end{array}\right.$

In (7) the CLP ends in a $\varphi$-break, but the DP does not; conversely, in (8) the DP ends in a $\varphi$ break, but the CLP does not. This indicates that there is some kind of restriction on the length of phonological phrase; precisely, a $\varphi$ is maximally tetrasyllabic. Speakers of iGeneration Taiwanese (iGT) seldom utter long expressions of this language; they tend to break a long string into short fragments and match them with smaller prosodic junctures. This tendency is reflected in the examples above.

4. Constraints and tableaux. In terms of classic OT (Prince \& Smolensky 1993/2004), the endbased approach is reframed under the notion of generalized alignment (McCarthy \& Prince 1993). In this sense, a set of alignment constraints and a set of $\varphi$-rhythm constraints are relevant, as posited in (9-10).

(9) Alignments

a. Align- $\mathrm{R}\left(\mathrm{XP}_{\mathrm{LEX}}, \varphi\right)$

Assign a violation mark for every $\mathrm{XP}_{\mathrm{Lex}}$ whose right edge does not coincide with that of a $\varphi$.

b. Align-R( $\left(\mathrm{XP}_{\mathrm{Fun}}, \varphi\right)$

Assign a violation mark for every $\mathrm{XP}_{\text {Fun }}$ whose right edge does not coincide with that of a $\varphi$.

c. Align- $\mathrm{R}\left(\varphi, \mathrm{XP}_{\mathrm{LEX}}\right)$

Assign a violation mark for every $\varphi$ whose right edge does not coincide with that of an $\mathrm{XP}_{\mathrm{LEX}}$.

d. Align- $\mathrm{R}\left(\varphi, \mathrm{XP}_{\mathrm{FuN}}\right)$

Assign a violation mark for every $\varphi$ whose right edge does not coincide with that of an $\mathrm{XP}_{\text {Fun. }}$. 
$\varphi$-rhythm

a. $\varphi$-MIN

Assign a violation mark for every $\varphi^{+a}$ that contains less than three syllables.

b. $\varphi$-MAX

Assign a violation mark for every $\varphi$ that contains more than four syllables.

The constraints ALIGN-R(XP $\left.\mathrm{XP}_{\mathrm{LEX}}, \varphi\right)$ and ALIGN-R(XP $\left.\mathrm{XPuN}_{\mathrm{Fu}}, \varphi\right)$ requires every lexical projection and functional projection respectively to be right-aligned with a phonological phrase. On the contrary, Align-R $\left(\varphi, \mathrm{XP}_{\mathrm{LEX}}\right)$ and ALIGN-R $\left(\varphi, \mathrm{XP}_{\mathrm{FuN}}\right)$ requires every phonological phrase to be rightaligned with a lexical projection and a functional projection respectively. The prosodic constraints $\varphi$-MIN and $\varphi$-MAX dictate that a phonological phrase is minimally trisyllabic but maximally tetrasyllabic. The constraint ranking is proposed as in (11).

(11) iGT constraint ranking

$\operatorname{Align}-\mathrm{R}\left(\mathrm{XP}_{\text {LeX }}, \varphi\right), \varphi-\operatorname{MAX}>>\varphi-\operatorname{Min}>>\operatorname{ALIGN}-\mathrm{R}\left(\varphi, \mathrm{XP}_{\text {LeX }}\right)>>$

$\operatorname{Align}-R\left(\mathrm{XP}_{\mathrm{Fun}}, \varphi\right), \operatorname{AlIGN}-\mathrm{R}\left(\varphi, \mathrm{XP}_{\mathrm{FuN}}\right)$

The top-ranking of ALIGN-R(XP $\left.\mathrm{XEX}_{\mathrm{LEX}}, \varphi\right), \varphi$-MAX ensures that every lexical projection is $\varphi$ marked, and that every phonological phrase is limited within four syllables. The constraint $\varphi$ MIN is ranked next such that a disyllabic phonological phrase may be allowed in violation of this constraint, which is suspended only when it contradicts ALIGN-R(XP $\left.\mathrm{XLX}_{\mathrm{LEX}}, \varphi\right)$. The bottom-ranking of $\operatorname{Align}-\mathrm{R}\left(\varphi, \mathrm{XP}_{\mathrm{LEX}}\right)$ and Align-R(XP $\left.\mathrm{PuN}_{\mathrm{FuN}}, \varphi\right)$ predicts two patterns: first, not every phonological phrase is aligned with a lexical projection, but it may sometimes be aligned with a functional projection; second, a functional projection must be $\varphi$-aligned if an oversized phonological phrase would emerge otherwise. The following tableaux show how this constraint ranking works.

\begin{tabular}{|c|c|c|c|c|c|}
\hline \multicolumn{6}{|c|}{ 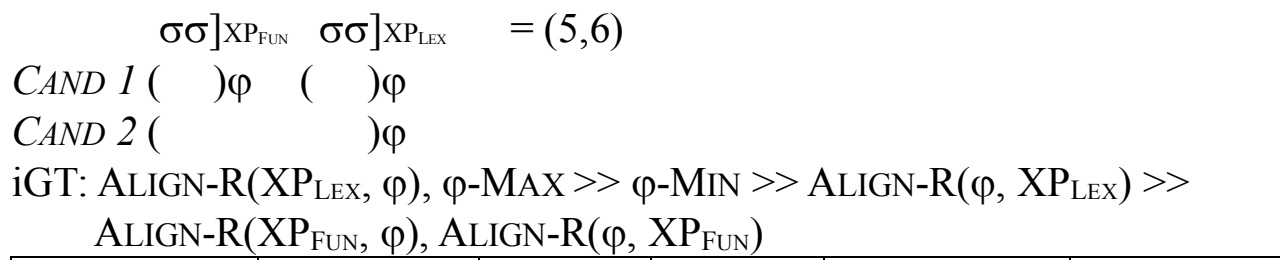 } \\
\hline & $\begin{array}{c}\text { ALIGN-R } \\
\left(\mathrm{XP}_{\mathrm{LEX}}, \varphi\right)\end{array}$ & $\varphi$-MAX & $\varphi$-MIN & $\begin{array}{c}\text { ALIGN-R } \\
\left(\varphi, X_{\text {LEX }}\right)\end{array}$ & $\begin{array}{c}\text { ALIGN-R } \\
(\mathrm{XP} \text { Fun, } \varphi)\end{array}$ \\
\hline CAND 1 & & & $* !$ & $*$ & \\
\hline CAND 2 & & & & & \\
\hline
\end{tabular}

In (12), CAND 1 is ruled out by $\varphi$-Min, which prevents the disyllabic $\mathrm{XP}_{\mathrm{Fun}}$ from being $\varphi$-aligned. CAND 2 thus emerges, and the line forms a tetrasyllabic phonological phrase. In (13), CAND 1 is parsed into three disyllabic phonological phrases, fatally incurring three violations of $\varphi$-MiN. CAND 3 constitutes a hexasyllabic phonological phrase, which is ruled out by $\varphi$-MAX. Finally, CAND 2 is selected as the optimal output, in spite of a violation of $\varphi$-MIN; as a consequence, the second $\mathrm{XP}_{\mathrm{Fun}}$ must be $\varphi$-aligned to avoid an oversized phonological phrase. 


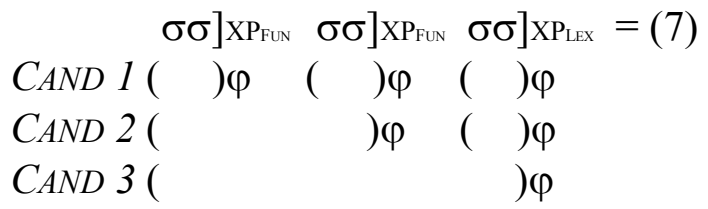

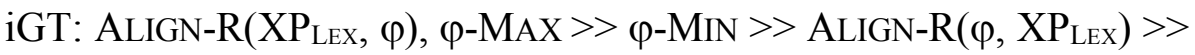
$\operatorname{Align-R}\left(\mathrm{XP}_{\mathrm{Fun}}, \varphi\right), \operatorname{ALIGN-R}\left(\varphi, \mathrm{XP}_{\mathrm{Fun}}\right)$

\begin{tabular}{|c|c:c|c|c:c|}
\hline & $\begin{array}{c}\text { ALIGN-R } \\
\left(\mathrm{XP}_{\text {LeX }}, \varphi\right)\end{array}$ & $\varphi$-MAX & $\varphi$-MiN & $\begin{array}{c}\text { ALIGN-R } \\
\left(\varphi, \mathrm{XP}_{\text {LeX }}\right)\end{array}$ & $\begin{array}{c}\text { ALIGN-R } \\
\left(\mathrm{XP}_{\mathrm{FuN}}, \varphi\right)\end{array}$ \\
\hline CAND 1 & & & $* * ! *$ & $* *$ & \\
\hline CAND 2 & & & $*$ & $*$ & $*$ \\
\hline CAND 3 & & $* !$ & & & $* *$ \\
\hline
\end{tabular}

Similarly, in (14), CAND 3 is chosen, as the other three candidates are eliminated either by $\varphi$ MAX or by $\varphi$-MIN. The line is then parsed into two tetrasyllabic phonological phrases.

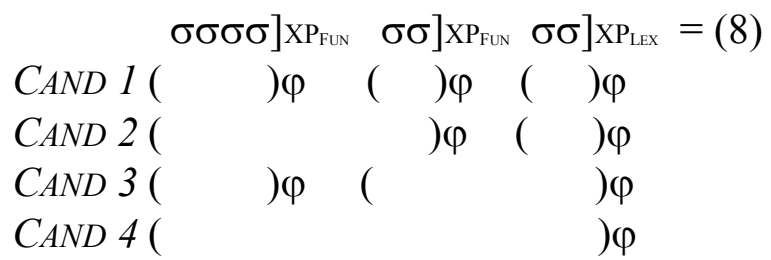

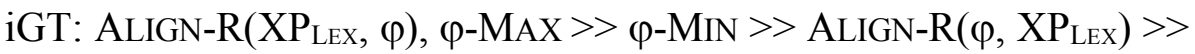
$\operatorname{ALIGN-R}\left(\mathrm{XP}_{\mathrm{FUN}}, \varphi\right), \operatorname{ALIGN-R}\left(\varphi, \mathrm{XP}_{\mathrm{FUN}}\right)$

\begin{tabular}{|c|c|c|c|c|c|}
\hline & $\begin{array}{c}\text { ALIGN-R } \\
\left(\mathrm{XP}_{\text {LEX }}, \varphi\right)\end{array}$ & $\varphi$-MAX & $\varphi$-MIN & $\begin{array}{l}\text { ALIGN-R } \\
\left(\varphi, \mathrm{XP}_{\text {LEX }}\right)\end{array}$ & $\begin{array}{c}\text { ALIGN-R } \\
\left(\mathrm{XP}_{\mathrm{FUN}}, \varphi\right)\end{array}$ \\
\hline CAND 1 & & & $* ! *$ & $* *$ & \\
\hline CAND 2 & & $* !$ & $*$ & $*$ & $*$ \\
\hline CAND 3 & & & & & $*$ \\
\hline CAND 4 & & $* !$ & & & $* *$ \\
\hline
\end{tabular}

5. Conclusion. General Taiwanese displays a distinction between lexical projection and functional projection; the former but not the latter ends in a phonological phrase break. The phonological phrase in iGeneration Taiwanese is affected by two factors: the type of syntactic projection and the number of syllable. I have proposed a set of alignment constraints and a set of rhythm constraints, and the interactions between these constraints achieve a non-derivational analysis. The proposed constraint ranking renders two predictions: first, a phonological phrase is maximally tetrasyllabic, and second, a functional projection ends in a $\varphi$-break only if a longer phonological phrase would be derived otherwise. This paper is a preliminary study for a twoyear research project. Further tasks include the establishment of a long-utterance corpus, a well as the investigation of the prosodic parsing of the longer utterances.

\section{References}

Alderete, John. 2008. Using learnability as a filter on factorial typology: A new approach to Anderson and Browne's generalization. Lingua 118. 1177-1220.

https://doi.org/10.1016/j.lingua.2008.03.002.

Abney, Steven. 1987. The English noun phrase in its sentential aspect. Camridge, MA: MIT dissertation. 
Blad, Evie. 2016. Teenagers' health, educational outcomes improving, report finds. Education Week. http://blogs.edweek.org/edweek/rulesforengagement/2016/06/teenagers_health_educa tional_outcomes_improving_report_finds.html. Accessed: December 1, 2018.

Barrie, Michael. 2006. Tone circles and contrast preservation. Linguistic Inquiry 37(1). 131-141. https://doi.org/10.1162/002438906775321148.

Chen, Matthew Y. 1987. The syntax of Xiamen tone sandhi. Phonology Yearbook 4. 109-150.

Chen, Matthew Y. 2000. Tone sandhi: Patterns across Chinese dialects. Cambridge, UK: Cambridge University Press.

Chomsky, Noam. 1986. Barriers. Camridge, MA: MIT Press.

Hsiao, Yuchau E. 1991. Syntax, rhythm and tone: A triangular relationship. San Diego: University of California dissertation. Published by Crane, Taipei.

Hsiao, Yuchau E. 1995. Southern Min tone sandhi and theories of prosodic phonology. Taipei: Student Book Co.

Hsiao, Yuchau E. 2015. Tonal chain shifts in Taiwanese: A comparative markedness approach. In Yuchau E. Hsiao \& Lian-hee Wee (eds.), Capturing phonological shades within and across languages. 142-165. Newcastle upon Tyne, UK: Cambridge Scholars Publishing.

Ouhalla, Jamal. 1991. Functional categories and parametric variation. London: Routledge.

Selkirk, Elizabeth. 1986. On derived domains in sentence phonology. Phonology Yearbook 3. 371-405.

Selkirk, Elizabeth. 2011. The Syntax-phonology interface. In John Goldsmith, Jason Riggle \& Alan C. L. Yu (eds.), The handbook of phonological theory, $2^{\text {nd }}$ edition. 435-484. Oxford: Blackwell.

Thomas, Guillaume. 2008. An analysis of Xiamen tone circle. In Natasha Abner \& Jason Bishop (eds.), Proceedings of the 27th West Coast Conference on Formal Linguistics. 422-430. Cambridge, MA: Cascadilla Press.

Truckenbrodt, Hubert. 1999. On the relation between syntactic phrases and prosodic phrases. Linguistic Inquiry 30(2). 219-255. https://doi.org/10.1162/002438999554048.

Wallop, Harry. 2014. Gen Z, Gen Y, baby boomers - a guide to the generations. The Telegraph. http://www.telegraph.co.uk/news/features/1 1002767/Gen-Z-Gen-Y-baby-boomers-a-guideto-the-generations.html. Accessed: November 12, 2018.

White, Shelley. 2016. The Generation Z effect. Canadian University Report 2016. https://www. theglobeandmail.com/news/national/education/canadian-university-report/the-genz-ef fect/article26898388/. Accessed: December 5, 2018. 